\title{
Relative safety of alternative intersection designs
}

\author{
L. C. Wadhwa ${ }^{1} \&$ M. Thomson ${ }^{2}$ \\ ${ }^{1}$ James Cook University Townsville Queensland Australia \\ ${ }^{2}$ Belmadar Construction Pty Ltd, Aitkenvale, Queensland, Australia
}

\begin{abstract}
Accidents at intersections in Queensland accounted for $45 \%$ of total accidents and $19 \%$ of fatal accidents on the State roads in 2002. The number of accidents at intersections is purported to be primarily correlated to the number of conflict points but geometric characteristics also influence intersection safety. Queensland Transport database of reported accidents over the past ten years has been used in this study to investigate the contribution of intersection design and characteristics on the relative safety of intersections. Queensland Transport's road crash database, WebCrash2, has been used to analyse the accident records at intersections in the Townsville region. The detailed analysis has included road user, vehicle type, collision type, BAC, use of seat belt and intersection type.

Considering the common variations in the number of approaches, entry and exit lanes, type of control, phase design for signalisation, the road environment and other features like flaring, channelisation and signage, each intersection is peculiar and unique in some way. However, research has been focussed on three main types of intersections. These include $\mathrm{T}$ junctions, cross intersections and roundabouts. Three levels of control are also considered. The objective is to relate the intersection safety to the number of conflict points, conflict types, and intersection geometry. The results show that roundabouts are the safest types of intersection while uncontrolled cross intersections are least safe. The level of safety decreases with the increase in the number of approaches and the number of conflict points.
\end{abstract}

Keywords: intersections, signalisation, roundabout, safety, conflict points, intersection control, accident analysis. 


\section{Introduction}

Accidents at intersections in Queensland accounted for $45 \%$ of total accidents and $19 \%$ of fatal accidents on the State roads in 2002 [1]. The number of accidents at intersections is purported to be primarily correlated to the number of conflict points but geometric characteristics also influence intersection safety. Queensland Transport database of reported accidents over the past ten years has been used in this study to investigate the contribution of intersection design and characteristics on the relative safety of intersections. Queensland Transport's road crash database, WebCrash2, has been used to analyse the accident records at intersections in the Townsville region. There are 2748 intersections in this region with an average of 318 accidents annually. The detailed analysis has included road user, vehicle type, collision type, BAC, use of seat belt and intersection type.

Considering the common variations in the number of approaches, entry and exit lanes, type of control, phase design for signalisation, the road environment and other features like flaring, channelisation and signage, each intersection is peculiar and unique in some way. However, research has been focused on three main types of intersections. These include $\mathrm{T}$ junctions, cross intersections and roundabouts. Three levels of control are also considered. The objective is to relate the intersection safety to the number of conflict points, conflict types, and intersection geometry. It has been found in this research that the level of intersection safety decreases with the increase in the number of approaches and the number of conflict points.

\section{Intersections}

Intersections are formed where two or more traffic streams merge, cross, or diverge and are an inevitable part of any road system. In most cases they cannot be avoided and are necessary in order for road users to obtain their desired destination. Motorists can change their direction and join a different traffic stream. Intersections cause delays to road users and are safety hazards, contributing to a significant share of road accidents.

\subsection{Design considerations}

The desirable objectives and considerations of intersection designs include:

1. provide maximum amount of comfort and safety for road users,

2. provide for the needs of all road users accessing the intersection,

3. ensure adequate capacity and minimum delays to drivers,

4. provide for necessary traffic movements,

5. separate and minimize number of conflict points throughout the intersection in order to maximize safety,

6. control speeds and give priority to major traffic streams,

7. minimize construction costs. 


\subsection{Intersection types}

Intersections are formed wherever two or more roads meet or cross. They allow vehicles to alter their course of driving by permitting them to make a turn. This may result in conflicting movements.

Intersections may vary in terms of geometric (physical) and traffic (operational) characteristics. These include:

- Number of approaches (legs),

- Lane configuration at each approach,

- Number of lanes,

- Movements permitted on each lane,

- Turning movements permitted for each approach,

- Type of control,

- Traffic volume,

- Traffic composition.

Intersections come in a variety of forms and sizes. Each intersection is unique in one way or the other. These may vary in physical characteristics, traffic flows and type of control. However, intersections can be grossly classified based on their specific characteristics. Most intersections are at-grade intersections Grade-separated intersections are, however, much safer. As the name implies, grade-separated intersections are those where the reduced levels separates the two traffic streams from merging, crossing or diverging at a location.

The number of traffic streams entering the intersection area is commonly used to classify intersections. The T-intersection (3 approaches or legs) and Cross intersection (4 approaches or legs) are the most common classifications. Intersections with the same number of approaches may still vary in design and alignment from one another. For example, intersections with 3 approaches may be $\mathrm{T}, \mathrm{T}$-skewed or $\mathrm{Y}$ intersections. Intersections with four approaches may be cross, skewed, skewed-cross or jogged intersection. Intersections containing more than four approaches are classified as multiple approach intersections. Roundabouts are a special type of intersections and are also classified according to number of approaches and number of lanes.

\subsection{Manoeuvres and conflicts}

Intersections account for almost half of all road crashes. Traffic movements at an intersection result in conflicting maneuvers.

Conflict points occur at intersections as result of two or more approaching traffic streams. Whether two traffic streams join, cross or divide, potential for conflict can arise. Traffic transferring from one stream into other results in a merging conflict. The most common types of incidents in these conflicts are sideswiping and rear ending. These have low relative speed. However the conflict can occur in areas closer to the passenger of vehicles such as driver's door and can be severe. Traffic streams intersecting through another traffic stream create a crossing conflict. Typical incident types involve right angle crashes and head-on crashes. They are the most severe of all conflicts and are 
most likely to involve injuries and fatalities. This is, in part, due to the high relative speeds between vehicles. Traffic separating itself from an existing traffic stream results in a diverging conflict. The most common incidents in this conflict situation involve rear end which is generally the least severe of the incidents. The relative speeds are usually low in such situations. In multi-lane sections of roads, weaving manoeuvre can cause conflicts. Weaving is basically a combination of a merge followed by a diverge manoeuvre. These conflicts can result in accidents in rear ending and sideswiping. Conflicts can also occur from queuing at intersections. These are generally rear end accidents and occur due to banking up of traffic or due to insufficient acceptance gap in major flow stop signs and lights.

The number of conflict points at an intersection depends on its configuration and control. Intersections with three approaches if unrestricted (all maneuvers allowed) and uncontrolled contain a total of nine conflict points -3 merging, 3 diverging and 3 crossing conflicts. Intersections with four approaches have a total of 32 conflict points -8 merging, 8 diverging and 16 crossing conflicts if they are unrestricted and uncontrolled. The traffic engineer is responsible for minimizing the number of conflict points. The engineer may have to trade-off the reduction in conflict points against intersection delay and capacity. Roundabouts have the ability to eliminate crossing conflict points in single lane flows. The number of conflict points in a single-lane roundabout can be found by doubling the number of approaches of which one half is merging and the remaining as diverging conflicts. The number of conflict points in various types of intersections and control are shown in Table 1.

Table 1: $\quad$ Conflict points based on intersection type and control.

\begin{tabular}{|l|l|c|}
\hline Intersection type & Control & No. of conflict points \\
\hline T-intersection (3-leg) & Uncontrolled & 9 \\
\hline & Signalised 2-phase & 4 \\
\hline & Signalised 3-phase & 3 \\
\hline $\begin{array}{l}\text { Cross intersection } \\
\text { (4-leg) }\end{array}$ & Uncontrolled & 36 \\
\hline & Signalised 2-phase & 16 \\
\hline & Signalised 4-phase & 8 \\
\hline Roundabout & 3-legs & 6 \\
\hline & 4-legs & 8 \\
\hline
\end{tabular}

\subsection{Safety of alternative intersection designs}

Some key ways of increasing safety at intersection [2] include:

1. minimizing the number of conflict points,

2. control relative speed,

3. separating points of conflicts,

4. reducing area of conflict,

5. controlling intersection design and traffic control considerations, 
6. controlling the speed and angle of traffic movements through channelisation,

7. prohibiting undesirable or unnecessary movements,

8. providing adequate capacity,

9. considering spacing of intersections.

Intersections in Queensland are governed by the basic right of way rule as is in the Traffic Act Legislation. This means giving way to your right and giving way at T-intersections. Difficulties are caused as intersections become more complicated such as multi-lane, multi-approach or skewed and/or in high flow conditions. There may be a need for installing control measures at the intersection. Controls are introduced at intersections for a variety of reasons but primarily from sound engineering and safety considerations. Some of these measures include the following [3]:

stop and give way sign

other signage control designating allowed maneuvers e.g. No Right Turns,

Left Lane Must Merge

other signage such as speed controls

channelisation

flaring

traffic signals

roundabouts

The objective of installing any traffic control system at an intersection is to make the intersection safer in one way or another and improving intersection performance. It should:

1. draw road users attention to the presence of conflicts and hazards,

2. control traffic movements into defined paths and locations,

3. restrict conflicting traffic movements with time separation,

4. inform road users of directions of destinations and traffic movements.

In examining the safety implications of intersection control, Frith and Harte [4] considered no control, simple stop or give way signs, roundabouts and signals at selected intersections in New Zealand. Signals and roundabouts were found to reduce accidents significantly at 3- and 4-leg intersection. Both significantly reduced accidents between vehicles from different roads while roundabouts performed much better than the signals for accidents between vehicles from the same road. Signage was found to significantly reduce accidents at 4-leg intersection, while a marginal decrease in severity of accidents at 3-leg intersections was observed.

Most pedestrian accidents occur at intersections. Gårder [5] found that of all pedestrian accidents in Sweden, 75\% happen in built-up areas of which about $80 \%$ occur at intersections. He examined 120 intersections in Sweden and found that signalization of a high speed intersection reduces pedestrian risk to approximately half. One way of reducing accidents caused by turning vehicles is to give the pedestrians a separate green phase, but this may increase both pedestrians and vehicles delay. Pedestrian safety is, however, not studied in detail in this study. 


\section{Intersection crash data analysis for Queensland}

Crash data are maintained by Queensland Transport on WebCrash2.

WebCrash2 is a program held by Queensland Transport capable of analyzing crash data in a variety of ways depending on the objectives of the analysis. The data fields in WebCrash2 include details of road users and vehicle(s) involved, location details, blood alcohol content of driver, seat restraint, collision details as well as the likely cause of the crash. More recently, intersection type is also recorded if the accident happened at or near an intersection.

\subsection{Recent crash data analysis}

Over the last 30 years, annual fatalities on Queensland roads have dropped by about 45\% from just under 600 to little over 300. Between 1999 and 2002, a total of 106,048 accidents occurred on Queensland roads of which 45,778 or roughly $43 \%$ happened at intersections. During the same period, these crashes resulted in 1557 fatalities of which 279 or roughly $18 \%$ happened at intersections.

The number of fatalities at intersections in Queensland has dropped from around 100 in 1993 to 55 in 2002. This is shown in Figure 1.

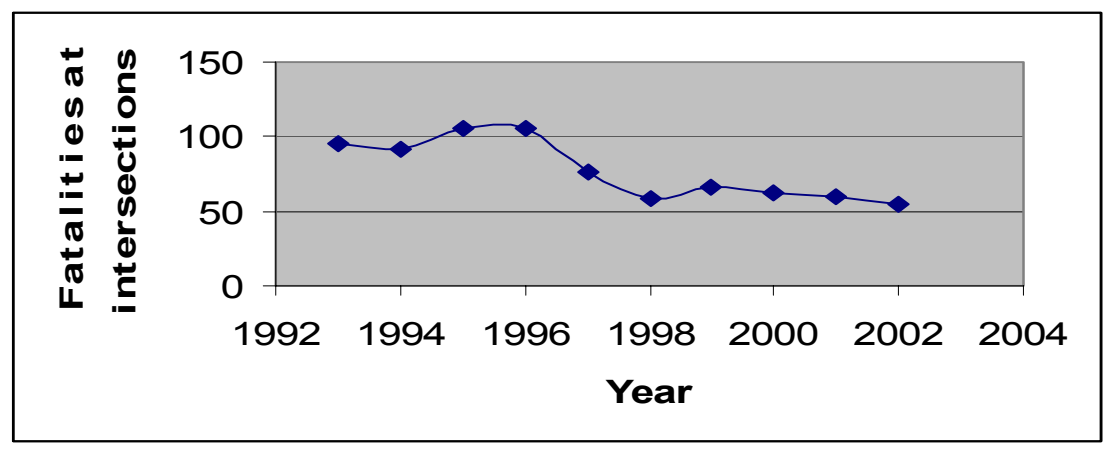

Figure 1: Reduction of fatal crashes at intersections in Queensland, 1993-2002

\subsection{Crashes and fatalities at intersections}

The distribution of crashes and fatalities at intersections by type of control are shown in Tables 2 and 3 for Queensland for the period 1999-2002.

Other data obtained from Queensland Transport show that crashes and fatalities have dropped by about $45 \%$ in spite of a $34 \%$ increase in the number of registered vehicles during the same period. Using the data in Tables 2 and 3, it is shown in Table 4 that the number of fatalities at roundabouts per 1000 crashes is 1.46 compared to 6.32 for $\mathrm{T}$-intersections and 5.83 for cross intersections. This is clear evidence confirming that roundabouts are the safest form of intersections. 
Table 2: $\quad$ Total crashes during 1999-2002, Queensland roads.

\begin{tabular}{|l|l|l|l|l|}
\hline Intersection type & No control & Signage & Traffic lights & Total \\
\hline Cross intersection & 3,220 & 6,050 & 9,756 & 19,026 \\
\hline T-intersection & 12,746 & 4,535 & 5,024 & 22,305 \\
\hline Roundabout & 454 & 3,650 & 3 & 4,107 \\
\hline Other & 58 & 79 & 203 & 340 \\
\hline Non-intersection & & & & 60,270 \\
\hline Total & 16,478 & 14,314 & 14,986 & 106,048 \\
\hline
\end{tabular}

Table 3: $\quad$ Fatal crashes during 1999-2002, Queensland roads.

\begin{tabular}{|l|l|l|l|l|}
\hline Intersection type & No control & Signage & Traffic lights & Total \\
\hline Cross intersection & 20 & 50 & 41 & 111 \\
\hline T-intersection & 97 & 27 & 17 & 141 \\
\hline Roundabout & 6 & 0 & 0 & 6 \\
\hline Other & 8 & 7 & 6 & 21 \\
\hline Non-intersection & & & & 1,278 \\
\hline Total & 131 & 84 & 64 & 1,557 \\
\hline
\end{tabular}

The type of control at an intersection has a significant bearing on the severity of crash and resulting fatalities. The proportion of fatal crashes at uncontrolled intersections is highest at 7.95 fatalities per 1000 crashes followed by intersections with signage with 5.87 fatalities and is least for intersections with traffic lights at 4.27 fatalities per 1000 crashes. This is also shown in Table 4.

\subsection{Relative safety of intersection types and control}

Annual crash and fatality data for 1999 to 2002 for Queensland has been analysed to obtain fatality rates based on the type and control of intersections. These are shown in Table 5.

Table 4: Number of fatalities per 1000 crashes during 1999-2002, Queensland roads.

\begin{tabular}{|l|l|l|l|l|}
\hline Intersection type & No control & Signage & Traffic lights & Total \\
\hline Cross intersection & 6.21 & 8.26 & 4.20 & 5.83 \\
\hline T-intersection & 7.61 & 5.95 & 3.38 & 6.32 \\
\hline Roundabout & 13.22 & 0 & 0 & 1.46 \\
\hline Other & 137.93 & 88.61 & 29.56 & 61.76 \\
\hline Non-intersection & & & & 21.20 \\
\hline Total & 7.95 & 5.87 & 4.27 & 14.68 \\
\hline
\end{tabular}


Table 5: Percentage of fatal accidents at intersections based on design and control.

Crashes

\begin{tabular}{|l|c|c|c|c|c|c|c|}
\hline \multirow{2}{*}{ Period } & \multicolumn{3}{|c|}{ Cross intersection } & \multicolumn{3}{c|}{ T-intersection } & Roundabout \\
\cline { 2 - 8 } & Signalised & Signed & $\begin{array}{c}\text { No } \\
\text { control }\end{array}$ & Signalised & Signed & $\begin{array}{c}\text { No } \\
\text { control }\end{array}$ & All \\
\hline 1999 & 1850 & 1188 & 668 & 843 & 786 & 2423 & 681 \\
\hline 2000 & 1854 & 1203 & 621 & 904 & 802 & 2426 & 689 \\
\hline 2001 & 2032 & 1174 & 644 & 1095 & 925 & 2598 & 841 \\
\hline 2002 & 1971 & 1245 & 642 & 1077 & 907 & 2594 & 923 \\
\hline Average & 1927 & 1203 & 644 & 980 & 855 & 2510 & 784 \\
\hline
\end{tabular}

Fatalities

\begin{tabular}{|l|c|c|c|c|c|c|c|}
\hline 1999 & 11 & 19 & 4 & 3 & 4 & 26 & 0 \\
\hline 2000 & 13 & 8 & 10 & 6 & 7 & 14 & 3 \\
\hline 2001 & 11 & 11 & 8 & 4 & 8 & 32 & 2 \\
\hline 2002 & 6 & 12 & 5 & 4 & 8 & 25 & 1 \\
\hline Average & 10.25 & 12.5 & 6.25 & 4.25 & 6.75 & 24.25 & 1.5 \\
\hline
\end{tabular}

$\%$ fatal

\begin{tabular}{|l|l|l|l|l|l|l|l|}
\hline $\begin{array}{l}1999- \\
2002\end{array}$ & 0.532 & 1.040 & 1.050 & 0.438 & 0.789 & 0.967 & 0.191 \\
\hline
\end{tabular}

It is obvious from Table 5 that roundabouts are the safest with $0.191 \%$ fatal accidents while uncontrolled cross intersections have a corresponding value of $1.05 \%$.

\subsection{Conflict point analyses}

Maycock and Hall have observed that an increase in crossing conflict points leads to a higher fatality rate [6]. Table 6 shows the number of crossing conflicts at intersections and the corresponding fatality rates.

Table 6 supports the premise that the fatality rate at an intersection increases with increase in number of crossing conflicts. This is also shown in Figure 2.

Table 6: Crossing conflicts versus fatality rates.

\begin{tabular}{|l|c|c|c|}
\hline Intersection type and control & $\begin{array}{c}\text { Number of } \\
\text { crossing conflict } \\
\text { points }\end{array}$ & $\begin{array}{c}\text { Number of } \\
\text { intersections in } \\
\text { Townsville }\end{array}$ & $\begin{array}{c}\text { Fatality } \\
\text { rate }\end{array}$ \\
\hline Roundabout & 0 & 128 & 0.191 \\
\hline Signalised T-intersections & 1 & 37 & 0.438 \\
\hline Signalised cross intersection & 2 & 46 & 0.532 \\
\hline Unsignalised T-intersection & 3 & 2129 & 0.878 \\
\hline $\begin{array}{l}\text { Unsignalised cross- } \\
\text { intersection }\end{array}$ & 16 & 408 & 1.05 \\
\hline
\end{tabular}




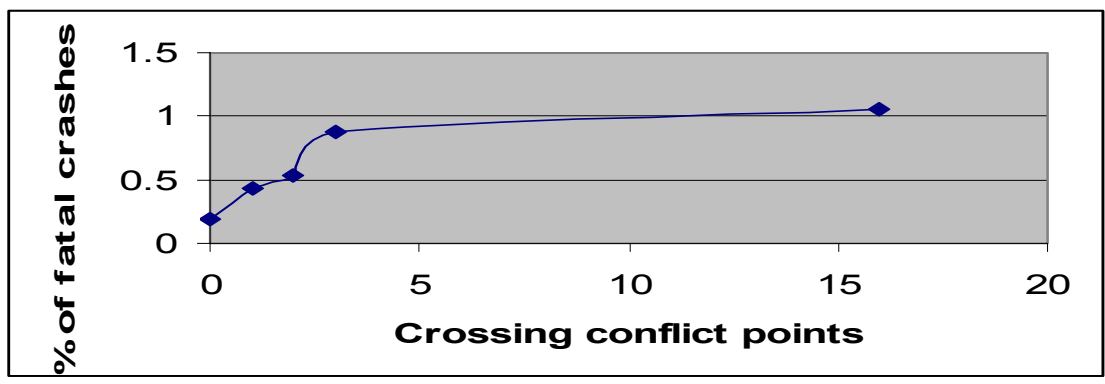

Figure 2: Proportion of fatal accidents as a function of crossing conflict points.

\section{Townsville accidents at intersections}

Using the results of analysis of relative safety of various intersection types and the number of intersections of various types in Townsville, an analysis has been carried out to predict the number of accidents in 2005 at Townsville intersections. The results are shown in Table 7. The analysis of new at-grade intersections show that on average there will be 1.135 accidents per year per intersection. The fatality rate at these intersections has been estimated at 0.005 .

Table 7: $\quad$ Predicted accidents at Townsville intersections 2005.

\begin{tabular}{|l|c|c|}
\hline Intersection type & No. of accidents & No. of fatal accidents \\
\hline Signalised cross intersection & 82 & 0.436 \\
\hline Signed cross intersection & 25 & 0.260 \\
\hline Uncontrolled cross intersection & 27 & 0.284 \\
\hline Signalised T-intersection & 42 & 0.184 \\
\hline Signed T-intersection & 19 & 0.150 \\
\hline Uncontrolled T-intersection & 107 & 0.844 \\
\hline Roundabouts & 34 & 0.065 \\
\hline Total & 338 & 2.223 \\
\hline
\end{tabular}

\subsection{Discussion and conclusions}

Intersections are an inevitable component of any road system. They are also sources of conflicting movements as drivers negotiate changes in direction or traffic streams to reach their destinations. Based on the number of approaches, traffic volumes and their turning movements, topography, lane widths and slopes, and the type of control, intersections take on a variety of designs, shapes and forms. In this study, the focus has been on three common types of intersections which are 3-leg and 4-leg intersections, and roundabouts. It has 
been found that the proportion of crashes and fatalities increases with increase in the number of conflict points.

It has been shown that the number of fatalities at roundabouts per 1000 crashes is 1.46 compared to 6.32 for $\mathrm{T}$-intersections and 5.83 for cross intersections. This is clear evidence confirming that roundabouts are the safest form of intersections. The type of control at an intersection has a significant bearing on the severity of crash and resulting fatalities. The proportion of fatal crashes at uncontrolled intersections is highest at 7.95 fatalities per 1000 crashes followed by intersections with signage with 5.87 fatalities and is least for intersections with traffic lights at 4.27 fatalities per 1000 crashes.

The number of expected crashes and fatalities at 2748 Townsville intersections has been estimated at 338 crashes and between 2 and 3 crashes respectively for 2005. The largest contribution to fatalities is from uncontrolled T-intersections followed by signalized cross intersections. These two intersection types make up almost $60 \%$ of all intersection crashes. Roundabouts contribute just three percent towards fatal crashes. Although most pedestrian accidents are found to occur at intersections, pedestrian safety at intersections has not been studied in this research.

\section{References}

[1] Queensland Transport (1999-2002) Road traffic crashes in Queensland Brisbane: Queensland Transport Fortitude Valley

[2] Ayers R (2002) Intersections, website http://www.usq.edu.au/users /ayers/tengmod07.htm\#topte07

[3] Henske D A and Button K J (2001) Handbook of transport systems and traffic control London: Pergamon Press

[4] Frith W J and Harte D S (1986) The safety implications of some control changes at urban intersections Analysis and Prevention 18 (3), 183-192

[5] Gårder, Per (1989) Pedestrian safety at traffic signals: A study carried out with the help of a traffic conflicts technique Accident Analysis and Prevention 21 (5), 435-444

[6] Maycock B and Hall S (1984) Accidents at 4-arm roundabouts, Crowthorne: TRL Report 